\title{
Influence of drying methods on quality of Zanthoxylum armatum DC. and mathematical modelling of the drying kinetics
}

\author{
Dong Xia, Lingyan Jiang, Jinxi Cheng, Xiaoyan Hou, Shanshan Li, Qingying Luo, Guanghui Shen, Hejun Wu, \\ Anjun Chen and Zhiqing Zhang* \\ College of Food Science, Sichuan Agricultural University, Ya'an, 625014, China.
}

\begin{abstract}
In order to evaluate different drying methods on the quality of Zanthoxylum armatum DC and the change of moisture content of $Z$ armatum during the drying process, the quality change was analyzed under three drying methods: Greenhouse drying equipment, Hot-air drying and Open sun-drying. The moisture loss was systematically recorded, converted to moisture ratio, and fitted to four semi-theoretical drying mathematical models: Lewis, Page, Henderson and Pabis, Avhad and Marchetti models. Comparisons of model fitness were using the coefficient of determination (R2), root mean square error (RMSE), mean bias error (MBE) and absolute error (MAE). The results showed that the color of $Z$ armatum obtained by the greenhouse drying equipment was bluish green, which was significantly different from the other two drying methods $(p<0.05)$. The numb degree difference of $Z$ armatum obtained by the three methods was not significant $(\mathrm{p}>0.05)$. The opening rate is better in greenhouse drying equipment and hot air $40^{\circ} \mathrm{C}$ drying. The content of linalool can reach $45.5738 \sim 55.3898 \%$ of the volatile oil. The drying mathematical models fitting results showed that Avhad and Marchetti models fitted best, and the R2 of the curve ranged from 0.9677 to 0.9967 , which could accurately predict the change trend of moisture ratio of $Z$ armatum in three drying methods with drying time.
\end{abstract}

\section{Introduction}

Zanthoxylum armatum DC also called "Qinghuajiao" in Chinese, belongs to family Rutaceae and is native to southeast and southwest China [1]. The peel contains a large amount of essential oil, which is usually used in flavoring food, traditional medicine and pharmaceutical industry and has a unique aroma similar to lemon, and can be used to prepare a variety of dishes to impart natural flavor [2], and has become a major feature of Chinese spices. Z armatum is mainly used in Sichuan cuisine, and it is required to retain its unique color, numb, and aroma. So the indicators in this article will consider color, numb, and aroma. In addition, due to the high moisture content of the freshly picked $Z$ armatum are susceptible to microbial degradation and the oil cell of $Z$ armatum is easily broken during transportation, which reduces the quality [3]. Fresh $Z$ armatum is not suitable for long-term storage. Therefore, $Z$ armatum should be dried for safe storage [4]. Drying is the most important process in the processing of fresh $Z$ armatum, which not only needs to reduce the moisture content of $Z$ armatum, but also needs to effectively control the browning of $Z$ armatum.

$Z$ armatum currently on the market is mainly dried in the form of natural and hot air. Research on drying has shown that it is a good alternative to producing high quality drying products [5]. The traditional open sun drying method is commonly used to produce $Z$ armatum because it is low input cost. However, the quality of dried products in the open air is low due to the contamination of foreign matter (garbage, dust, soil and sand) and the long time required for drying [6]. Hot air drying requires high investment and high energy consumption. Greenhouse drying is considered as a promising alternative to fruit and vegetable drying in developing countries because it has the lowest operating cost in terms of fuel costs [7]. It is also a more convenient option for rural areas and other areas where electricity supplies are scarce or unstable [8]. Studies have shown that the highest temperature of the greenhouse can reach $49^{\circ} \mathrm{C}$, which is far higher than the maximum temperature of the air outside the greenhouse, which is $32.8^{\circ} \mathrm{C}$. The time of drying pepper in the greenhouse is shorter [9]. Panwar [10] designed a dryer that could dry 600 kilograms of cotton in a day, reducing the water content from $40 \%$ to $5 \%$.

In the process of drying, it is necessary to understand the internal law of drying. Mathematical model is an important aspect of simulating drying process in drying technology. Existing mathematical models used to predict the drying process of different biomaterials include Lewis model [11], Page model [12], Henderson and Pabis model [13], Avhad and Marchetti model [14]. The Lewis model is the simplest model because it contains only one model constant and now widely used to describe the drying behavior of different agricultural products [15]. Page model is a modification of Lewis model that contains two model constants. Henderson and

\footnotetext{
*Corresponding author: zqzhang721@163.com
} 
Pabis model is related to Fick's second law, also known as two-parameter exponential models [16]. Avhad and Marchetti improved the Page and the Henderson and Pabis model to get the Avhad and Marchetti model [17]. Dissa used Lewis model, Page model, Henderson and Pabis model to fit the drying dynamics of mango slices, and found that Page model was the most suitable model to describe the thin layer drying characteristics of mango slices. Henderson and Pabis model produced a good fit in predicting citrus seed drying [18]. Keneni [19] used Lewis model, Page model, Henderson and Pabis model, Avhad and Marchetti model to fit the mathematical model of Jatropha seed drying kinetics, and the results showed that Avhad and Marchetti model provided more reliable experimental data fitting.

In order to solve the shortcomings of the above methods, this work designed a greenhouse drying equipment, using forced convection mode of solar energy to dry $Z$ armatum. Greenhouse drying equipment can use solar energy more efficiently, low investment, and can be used to dry a variety of fruits, thereby bringing better economic benefits [20]. The effect of greenhouse drying equipment compares with traditional natural drying and hot air drying, studies the effects of different drying methods on $Z$ armatum quality, and combines four mathematical models to fit the drying process under different drying conditions to fit the most suitable mathematical model to predict the drying kinetics of $Z$ armatum under three treatments.

\section{Materials and methods}

\subsection{Materials and equipment}

\subsubsection{Raw Materials}

Fresh fruit of $Z$ armatum, collected from Santai County, Mianyang City, Sichuan Province in July 2019. Methanol was purchased from Chengdu CHRON CHEMICALS co. LTD.

\subsubsection{Instruments and equipment}

101-2EBS Air Circulation Oven from Beijing ever bright medical treatment instrument co., LTD; Greenhouse drying equipment; HZY-A320Electronic scales from Connecticut HZ electronic technology co., LTD; CS-10 Colorimeter from CHN Spec co., LTD; UV-Vis spectrophotometer measurement from Shanghai Mepi instrument Co., LTD. Agilent 7890A-575C Gas Chromatography-Mass Spectrometer:

The dimension of the designed even span roof type greenhouse dryer is $35 \mathrm{~cm} * 35 \mathrm{~cm} * 65 \mathrm{~cm}$. Trays are fabricated with stainless steel wire meshed having the dimension $24 \mathrm{~cm} * 30 \mathrm{~cm}$. These are placed on the runner at $17 \mathrm{~cm}$ height. There are 4 and 1 fans with a diameter of $12 \mathrm{~cm}$ and a power of $21 \mathrm{~W}$ at the bottom and top of the device, respectively, to ensure sufficient air exchange under and around $Z$ armatum fruit. Figure 1 shows greenhouse drying equipment.

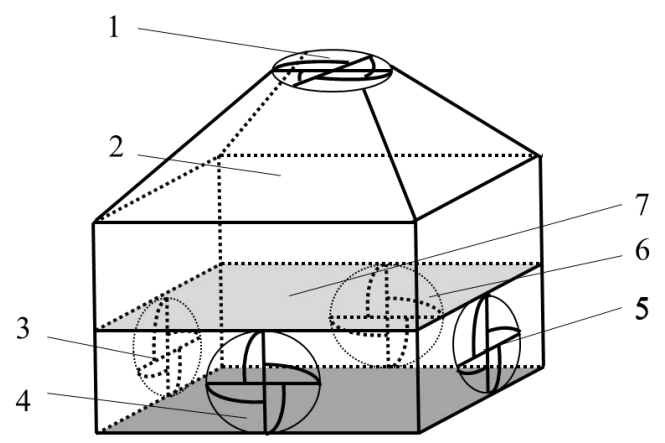

1-Air outlet fan, 2- Outer wall of greenhouse, 3, 4, 5, 6- Air inlet fan, 7- Tray place

Figure 1. Greenhouse drying equipment

\subsection{Methods}

The moldy and diseased fruit in the fresh $Z$ armatum picked out, weigh the selected $Z$ armatum samples and dry them according to different drying conditions (Greenhouse/Open sun/ Hot air 40, 45, 50, 55, 60 ${ }^{\circ} \mathrm{C}$ ) for 680 minutes. After the drying, $Z$ armatum was seeded and debranched, and stored in a sealed bag at $4{ }^{\circ} \mathrm{C}$ for future use.

\subsection{Determination of quality index}

\subsubsection{Color measurement}

The color difference was determined according to Al-Ismaili method [4]. Take an appropriate amount of dried $Z$ armatum and crush it through a 100 mesh sieve. Make sure that the $Z$ armatum powder is spread on the white paper, and then use the color difference meter to determine the Llalb value of the sample (Because basically want to see the green circumstance of cane $Z$ armatum, notice to see a value, did not calculate E). Repeat twice and average.

\subsubsection{Numb degree}

The numb degree of $Z$ armatum was determined by UV-Vis spectrophotometer measurement (UV-1800PC, Shanghai Mepi instrument Co., Ltd, China). Samples were taken every two hours during the drying period, 
and numb degree was determined by spectrophotometry. The hydroxyl- $\alpha$-sanshool weighed precisely was dissolved and diluted with methanol, and then formulated into $1,2,3,4,5,6 \mu \mathrm{g} / \mathrm{ml}$ standard solution, the absorption of which were survived at $268 \mathrm{~nm}$ with methanol as the blank, respectively. The linear regression of absorption on concentration was made and the regression equation was calculated. The standard curve was drawn and its equation was $\mathrm{y}=7.1554 \mathrm{x}+0.0254$, $\mathrm{R}^{2}=0.9997$. Ten samples were randomly selected each time. The seeds were deseeded to retain the $Z$ armatum peel. After grinding, $0.02 \mathrm{~g}$ of the sample was placed in a centrifuge tube, $3 \mathrm{~mL}$ of methanol was added, and the mixture was centrifuged for 10 minutes after sonication for 20 minutes. After the supernatant was removed, methanol was added again. Ultrasonic and centrifugation again, mix the supernatant with the previous supernatant in a constant volume of $10 \mathrm{ml}$. After the solution was diluted 500 times, the absorbance $A$ was measured at a wavelength of $268 \mathrm{~nm}$. Each experiment was repeated twice to take the average value. The formula for calculating the numb $K$ is as follows:

$$
K=\frac{(7.1554 * A+0.0254) * n}{1000 * m}
$$

where, $K$ is numb degree; $A$ is the absorbance at 268 $\mathrm{nm}$ of the hydroxy- $\alpha$-sanshool; $\mathrm{n}$ is dilution factor; $\mathrm{m}$ is the sample mass $(\mathrm{g})$.

\subsubsection{Opening rate}

100 samples were randomly selected from the dried $Z$ armatum samples. Recorded the sufficient number of openings $n$, that is the number of particles that are completely separated from the peel and seeds[21]. The calculation formula of opening rate $\eta$ is as follows:

$$
\eta=\frac{n}{100} \times 100 \%
$$

where, $\eta$ is opening rate; $n$ is the number of open particles.

\subsubsection{Moisture content}

The initial moisture content was obtained by constant temperature drying at $105^{\circ} \mathrm{C}[22]$. The samples were taken out and weighed at intervals of 20 min during the drying period, and the samples were quickly put into the drying equipment. Repeat the operation until the end of drying. The moisture content $\mathrm{M}_{\mathrm{t}}$ is calculated according to the following formula.

$$
M_{t}=\frac{m_{t}-m}{m}
$$

where, $m_{t}$ is the mass of the sampled material at a certain time $\mathrm{t}(\mathrm{g}) ; m$ is the equilibrium mass of the material $(\mathrm{g})$.

$Z$ armatum moisture content ratio $\mathrm{MR}$ calculation formula is as follows:

$$
M R=\frac{M_{t}}{M_{0}}
$$

where, $M_{0}$ is the initial moisture content of the sample.

\subsubsection{Volatile oil}

Steam distillation method [23]: accurately weigh $20 \mathrm{~g}$ of $Z$ armatum, crushed to 40 mesh, placed in a $1000 \mathrm{~mL}$ flat-bottomed flask, added $500 \mathrm{~mL}$ of ultra-pure water, heated boiling, adjust the electric furnace power to maintain reflux $4 \mathrm{~h}$, after distillation is finished, the extracted volatile oil with chromatographic pure hexane diluted 50 times over $0.22 \mu \mathrm{m}$ of microporous filter membrane for use.

The chromatographic conditions were as follows: HP-5MS $(30 \mathrm{~m} \times 0.25 \mu \mathrm{m} \times 0.25 \mu \mathrm{m})$ elastic quartz capillary column; The programmed temperature was as follows: the initial column temperature was $50^{\circ} \mathrm{C}$ for 3 $\min$, then increased to $120^{\circ} \mathrm{C}$ at a rate of $10^{\circ} \mathrm{C} / \mathrm{min}$ for 2 $\mathrm{min}$, and finally increased to $260^{\circ} \mathrm{C}$ at a rate of $5^{\circ} \mathrm{C} / \mathrm{min}$ for $5 \mathrm{~min}$. The carrier gas was high purity $\mathrm{HE}$, and the flow rate was $1.0 \mathrm{~mL} / \mathrm{min}$. The injector temperature was $250^{\circ} \mathrm{C}$, the detector temperature was $260^{\circ} \mathrm{C}$, the injection volume was $1 \mu \mathrm{L}$.

Mass spectrometric conditions: electron bombardment ion source, electron energy $70 \mathrm{eV}$; Ion source temperature $230{ }^{\circ} \mathrm{C}$; Interface temperature 280 ${ }^{\circ} \mathrm{C}$; Four bar temperature $150{ }^{\circ} \mathrm{C}$; Solvent delay of 4 min; The scanning range was 20-600 amu, and the scanning interval was $0.5 \mathrm{~s}$. Then, the components with a matching rate greater than $85 \%$ were counted through NIST11.1 spectrum database retrieval.

\subsection{Statistical Analysis}

Table 1 shows the mathematical dynamic model: Lewis model, Page model, Henderson and Pabis model, Avhad and Marchetti model. In this experiment, the weight loss data measured by $Z$ armatum samples under different drying methods and drying times were converted into moisture content data for the study of drying kinetics fitting. Fitting mathematical model of $Z$ armatum moisture content ratio as a function of time.

Microsoft Excel 2010 software was used to organize the data, MATLAB 2014 software was used to process experimental data and statistical analysis including Duncan test (differences considered significant at $p<$ 0.05 ), and Origin 9.0 software was used to plot.

\section{Results and discussion}

\subsection{Influence of $Z$ armatum fruit color with different drying conditions}

Dried $Z$ armatum obtained under different conditions including greenhouse drying, open sun drying, hot air drying. Figure 2 shows that the color of $Z$ armatum in the drying oven gradually deepens with the rise of temperature. Value $a^{*}$ is an important indicator for evaluating whether $Z$ armatum is still green after drying. It can be known from Table 2 that as the drying temperature of the oven increases, the value of $a^{*}$ increases, and the color development gradually changes from green to yellowish brown, so the drying temperature has a greater impact on the color and luster of $Z$ armatum. Comparison of greenhouse drying, Open 
sun drying and hot air drying, there was a significant difference in a* value $(p<0.05)$. The sorting according to $\mathrm{a}^{*}$ is: $55^{\circ} \mathrm{C}(4.65)>60^{\circ} \mathrm{C}(2.77)>$ Open sun $(0.13)$ $>50^{\circ} \mathrm{C}(-1.44)>45^{\circ} \mathrm{C}(-1.64)>40^{\circ} \mathrm{C}(-6.46)>$ Greenhouse $(-7.27)$. The a $*$ value of greenhouse drying equipment is the smallest $(-7.27)$ and the color is turquoise. The $Z$ armatum color obtained by drying at higher temperature tends to be yellow and gradually darkens with the increase of temperature, Sriwichai has a similar phenomenon in $Z$ armatum study of microwave drying [23]. Indicating that the use of the greenhouse drying equipment has no significant on the color of $Z$ armatum, and the color quality of dry $Z$ armatum was better.

Table 1. Drying parameters of the model

\begin{tabular}{|c|c|c|c|c|c|c|c|}
\hline Model & $\begin{array}{c}\text { Mode } \\
\text { equation }\end{array}$ & $\begin{array}{c}\text { Dry } \\
\text { conditions }\end{array}$ & Parameter & $\mathrm{R}^{2}$ & RMSE & MBE & MAE \\
\hline \multirow{7}{*}{ Lewis } & \multirow{7}{*}{$\begin{array}{l}M R \\
=\exp (-k t)\end{array}$} & Greenhouse & $\mathrm{k}=0.00135$ & 0.9661 & 0.0317 & 0.0292 & 0.0292 \\
\hline & & Open sun & $\mathrm{k}=0.00135$ & 0.9348 & 0.0433 & 0.0398 & 0.0398 \\
\hline & & $40^{\circ} \mathrm{C}$ & $\mathrm{k}=0.0016$ & 0.9035 & 0.0545 & 0.0503 & 0.0503 \\
\hline & & $45^{\circ} \mathrm{C}$ & $\mathrm{k}=0.0016$ & 0.9309 & 0.0563 & -0.0520 & 0.0520 \\
\hline & & $50^{\circ} \mathrm{C}$ & $\mathrm{k}=0.00185$ & 0.9104 & 0.0681 & -0.0635 & 0.0635 \\
\hline & & $55^{\circ} \mathrm{C}$ & $\mathrm{k}=0.0036$ & 0.9048 & 0.0773 & 0.0744 & 0.0744 \\
\hline & & $60^{\circ} \mathrm{C}$ & $\mathrm{k}=0.00425$ & 0.9189 & 0.0682 & 0.0571 & 0.0571 \\
\hline \multirow{7}{*}{$\begin{array}{l}\text { Handerson } \\
\& \text { Pabis }\end{array}$} & \multirow{7}{*}{$\begin{array}{l}M R \\
=a \exp (-k t)\end{array}$} & Greenhouse & $\begin{array}{c}\mathrm{a}=1.059 \\
\mathrm{k}=0.0012\end{array}$ & 0.9637 & 0.0328 & -0.0307 & 0.0307 \\
\hline & & Open sun & $\begin{array}{l}\mathrm{a}=1.004 \\
\mathrm{k}=0.001\end{array}$ & 0.9517 & 0.0373 & -0.0244 & 0.0303 \\
\hline & & $40^{\circ} \mathrm{C}$ & $\begin{array}{c}\mathrm{a}=1.02 \\
\mathrm{k}=0.001201\end{array}$ & 0.9543 & 0.0375 & -0.0367 & 0.0367 \\
\hline & & $45^{\circ} \mathrm{C}$ & $\begin{array}{c}\mathrm{a}=1.015 \\
\mathrm{k}=0.0017\end{array}$ & 0.9526 & 0.0467 & -0.0444 & 0.0444 \\
\hline & & $50^{\circ} \mathrm{C}$ & $\begin{array}{l}\mathrm{a}=1.004 \\
\mathrm{k}=0.002\end{array}$ & 0.9574 & 0.0469 & -0.0435 & 0.0435 \\
\hline & & $55^{\circ} \mathrm{C}$ & $\begin{array}{c}\mathrm{a}=1.016 \\
\mathrm{k}=0.0024\end{array}$ & 0.9516 & 0.0551 & -0.0513 & 0.0513 \\
\hline & & $60^{\circ} \mathrm{C}$ & $\begin{array}{c}\mathrm{a}=1.007 \\
\mathrm{k}=0.0032\end{array}$ & 0.9514 & 0.0528 & -0.0248 & 0.0471 \\
\hline Model & $\begin{array}{c}\text { Mode } \\
\text { equation }\end{array}$ & $\begin{array}{c}\text { Dry } \\
\text { conditions }\end{array}$ & Parameter & $\mathrm{R}^{2}$ & RMSE & $\mathrm{MBE}$ & MAE \\
\hline \multirow{7}{*}{ Page } & \multirow{7}{*}{$\begin{array}{l}M R \\
=\exp \left(-k t^{N}\right)\end{array}$} & Greenhouse & $\mathrm{k}=0.0068 \mathrm{~N}=0.699$ & 0.9136 & 0.0507 & -0.0006 & 0.0453 \\
\hline & & Open sun & $\mathrm{k}=0.0067 \mathrm{~N}=0.7$ & 0.9154 & 0.0493 & 0.0078 & 0.0446 \\
\hline & & $40^{\circ} \mathrm{C}$ & $\mathrm{k}=0.012 \mathrm{~N}=0.63$ & 0.9213 & 0.0493 & 0.0081 & 0.0430 \\
\hline & & $45^{\circ} \mathrm{C}$ & $\mathrm{k}=0.015 \mathrm{~N}=0.66$ & 0.9326 & 0.0557 & 0.0203 & 0.0494 \\
\hline & & $50^{\circ} \mathrm{C}$ & $\mathrm{k}=0.014 \mathrm{~N}=0.67$ & 0.9105 & 0.0680 & -0.0347 & 0.0602 \\
\hline & & $55^{\circ} \mathrm{C}$ & $\mathrm{k}=0.0137 \mathrm{~N}=0.7$ & 0.9030 & 0.0780 & -0.0427 & 0.0690 \\
\hline & & $60^{\circ} \mathrm{C}$ & $\mathrm{k}=0.024 \mathrm{~N}=0.69$ & 0.9233 & 0.0664 & 0.0531 & 0.0531 \\
\hline \multirow{7}{*}{$\begin{array}{l}\text { Avhad \& } \\
\text { Marchetti }\end{array}$} & \multirow{7}{*}{$\begin{array}{l}M R \\
=\operatorname{aexp}\left(-k t^{N}\right)\end{array}$} & Greenhouse & $\mathrm{a}=1.02 \mathrm{k}=0.0009 \mathrm{~N}=1.05$ & 0.9967 & 0.0099 & -0.0017 & 0.0083 \\
\hline & & Open sun & $\mathrm{a}=1.02 \mathrm{k}=0.0009 \mathrm{~N}=1.044$ & 0.9902 & 0.0168 & 0.0002 & 0.0130 \\
\hline & & $40^{\circ} \mathrm{C}$ & $\mathrm{a}=1.02 \mathrm{k}=0.001 \mathrm{~N}=1.052$ & 0.9939 & 0.0138 & -0.0052 & 0.0115 \\
\hline & & $45^{\circ} \mathrm{C}$ & $\mathrm{a}=1.02 \mathrm{k}=0.001 \mathrm{~N}=1.113$ & 0.9854 & 0.0259 & -0.0091 & 0.0207 \\
\hline & & $50^{\circ} \mathrm{C}$ & $\mathrm{a}=1.03 \mathrm{k}=0.014 \mathrm{~N}=0.7$ & 0.9710 & 0.0387 & 0.0045 & 0.0328 \\
\hline & & $55^{\circ} \mathrm{C}$ & $\mathrm{a}=1.08 \mathrm{k}=0.018 \mathrm{~N}=0.697$ & 0.9677 & 0.0450 & 0.0053 & 0.0400 \\
\hline & & $60^{\circ} \mathrm{C}$ & $\mathrm{a}=1.08 \mathrm{k}=0.021 \mathrm{~N}=0.7$ & 0.9801 & 0.0338 & 0.0006 & 0.0291 \\
\hline
\end{tabular}

Table 2. Quality of $Z$ armatum in different drying conditions

\begin{tabular}{cccccccc}
\hline Quality & Greenhouse & Open sun & $40^{\circ} \mathrm{C}$ & $45^{\circ} \mathrm{C}$ & $50^{\circ} \mathrm{C}$ & $55^{\circ} \mathrm{C}$ & $60^{\circ} \mathrm{C}$ \\
\hline$L^{*}$ & $45.62 \pm 1.265^{\mathrm{a}}$ & $31.28 \pm 0.62^{\mathrm{d}}$ & $37.94 \pm 0.025^{\mathrm{b}}$ & $35.36 \pm 0.17^{\mathrm{c}}$ & $30.52 \pm 1.165^{\mathrm{d}}$ & $25.77 \pm 0.47^{\mathrm{e}}$ & $25.40 \pm 0.365^{\mathrm{e}}$ \\
$\mathrm{a}^{*}$ & $-7.27 \pm 0.285^{\mathrm{f}}$ & $0.13 \pm 0.215^{\mathrm{c}}$ & $-6.46 \pm 0.135^{\mathrm{e}}$ & $-1.64 \pm 0.075^{\mathrm{d}}$ & $-1.44 \pm 0.225^{\mathrm{d}}$ & $4.65 \pm 0.26^{\mathrm{a}}$ & $2.77 \pm 0.01^{\mathrm{b}}$ \\
$\mathrm{b}^{*}$ & $32.63 \pm 0.84^{\mathrm{a}}$ & $24.76 \pm 0.15^{\mathrm{d}}$ & $31.76 \pm 0.905^{\mathrm{a}}$ & $28.16 \pm 0.285^{\mathrm{b}}$ & $26.79 \pm 0.32^{\mathrm{bc}}$ & $25.45 \pm 0.57^{\mathrm{cd}}$ & $22.82 \pm 0.235^{\mathrm{e}}$ \\
Opening rate & $98.67 \%$ & $96.67 \%$ & $99.00 \%$ & $93.00 \%$ & $93.33 \%$ & $90.33 \%$ & $90.00 \%$ \\
\hline
\end{tabular}

Within the same column, values with different letters indicate significant differences $(p<0.05)$. 


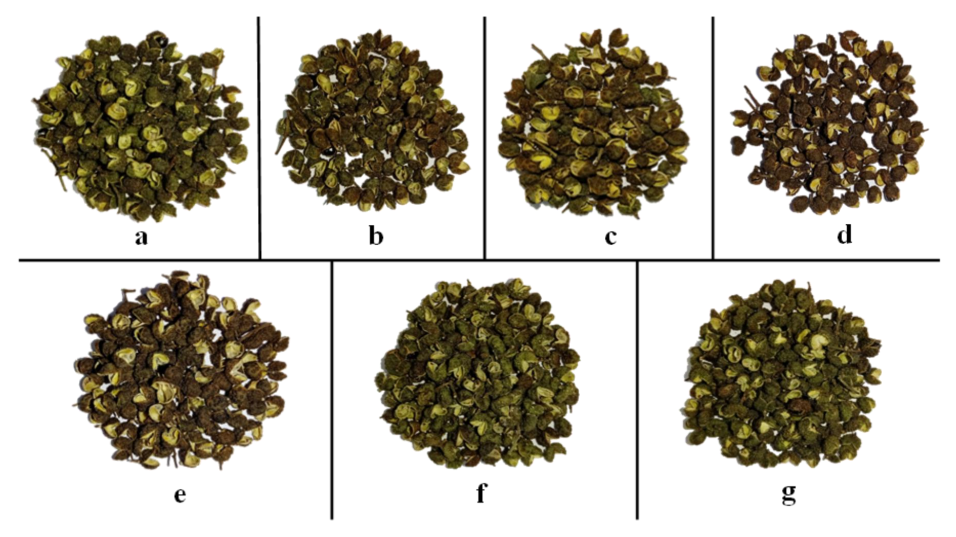

a e. Hot air at $40^{\circ} \mathrm{C}, 45^{\circ} \mathrm{C}, 50^{\circ} \mathrm{C}, 55^{\circ} \mathrm{C}$ and $60^{\circ} \mathrm{C}$ respectively; f. Open sun drying; g. Greenhouse drying

Figure 2. $\mathrm{Z}$ armatum products under different drying conditions

\subsection{Influence of numb degree on $\mathrm{Z}$ armatum with different drying conditions}

From Figure 3, the $Z$ armatum numb degree under 7 dry conditions increased first and then gradually decreased with the extension of time. Ten hours before drying, the $Z$ armatum numb degree under various conditions gradually increased from 9.2182, and began to decrease after reaching the peak (Greenhouse: 132.5042; Open sun: 118.6005 , Hot air $40^{\circ} \mathrm{C}: 115.4150 ; 45^{\circ} \mathrm{C}: 132.3197$; $\left.50^{\circ} \mathrm{C}: 117.5039 ; 55^{\circ} \mathrm{C}: 100.5753 ; 60^{\circ} \mathrm{C}: 101.6222\right)$. The results showed that in the early stage of drying, with the rapid decrease of water content of $Z$ armatum, the proportion of numb flavor substances was larger when equal quality $Z$ armatum was taken, and the numb degree increased in the later stage. However, the main numb flavor substance of $Z$ armatum is hydroxy zanthoxylin, which is not stable to heat. The numb flavor substance is damaged by heating for a long time and at a higher temperature $[24,25]$. Therefore, the numb degree of $Z$ armatum is relatively low in the later stage of drying, especially in the oven at $55^{\circ} \mathrm{C}$. According to Figure 3, with the increase of oven temperature, the $Z$ armatum numb degree at the end of drying shows a decreasing trend: $117.16^{\mathrm{a}}\left(45^{\circ} \mathrm{C}\right)>112.07^{\mathrm{a}}\left(40^{\circ} \mathrm{C}\right)>$ $101.98^{\mathrm{ab}}\left(50^{\circ} \mathrm{C}\right)>81.06^{\mathrm{b}}\left(60^{\circ} \mathrm{C}\right)>77.96^{\mathrm{b}}\left(55^{\circ} \mathrm{C}\right)$, but there is no significant difference in the $Z$ armatum numb degree of oven at $40^{\circ} \mathrm{C}, 45^{\circ} \mathrm{C}$ and $50^{\circ} \mathrm{C}$, Open sun and greenhouse drying equipment $(p<0.05)$.

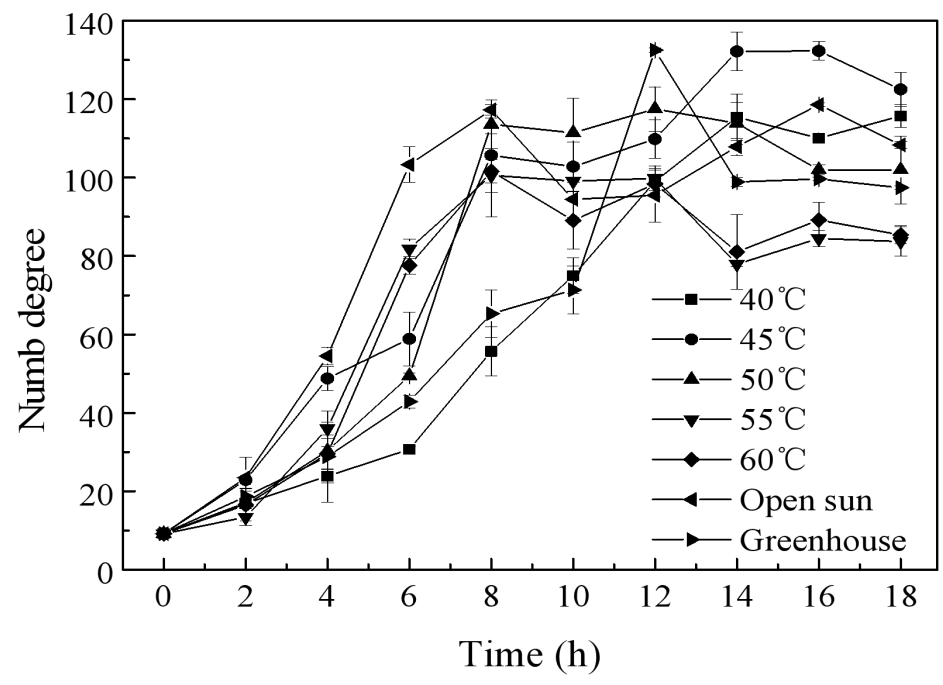

Figure 3. Numb degree variation of $Z$ armatum with drying time

\subsection{Influence of opening rate of $Z$ armatum with different drying conditions}

The opening rate was more than $90 \%$ under the 7 conditions, and there was no significant difference between oven $40^{\circ} \mathrm{C}$ and greenhouse $(p<0.05)$; moreover, the opening rate decreased with the increase of temperature. The opening rate of $Z$ armatum dried at $40^{\circ} \mathrm{C}$ was the highest, which was higher than other temperature gradients. Therefore, the opening rate of $Z$ armatum dried at $40^{\circ} \mathrm{C}$ is better than other temperature 
conditions, as shown in Table 2.

\subsection{Influence of moisture ratio of $Z$ armatum with different drying conditions}

Dry the $Z$ armatum with a laying thickness of $3 \mathrm{~cm}$ under different conditions to obtain the relationship between moisture content ratio and time (MR / T), as shown in Figure 4 . With the increase of drying time, the moisture ratio gradually decreases. MR decreased from 1 to 0.4463 (Greenhouse), 0.0.4964 (Sun), $0.4019\left(40^{\circ} \mathrm{C}\right)$, $0.2689\left(45^{\circ} \mathrm{C}\right), 0.2337\left(50^{\circ} \mathrm{C}\right), 0.1781\left(55^{\circ} \mathrm{C}\right), 0.1920$ $\left(60^{\circ} \mathrm{C}\right)$, respectively. And the slope of the MR T graph in the initial drying stage is higher than that in the latter half. The reason is that the dry medium -- hot air, in the case of higher temperature, increases the temperature difference between air and $Z$ armatum surface, increases the heat transfer impetus, resulting in faster heat transfer speed; when the ambient water content is constant, the higher the air temperature, the relative humidity of the air will decrease, which increases the humidity difference with the sample, and accelerates the mass transfer driving force, which accelerates mass transfer; In addition, the increase of temperature will accelerate the thermal movement of water molecules, causing the water molecules to diffuse faster in the sample [26]. The higher the drying temperature, the faster the rate of decrease of the moisture ratio. The reason is that the increase in temperature increases the vapor pressure difference between the dry air and $Z$ armatum. When the drying time reaches $680 \mathrm{~min}$, the $Z$ armatum moisture content ratio in the open sun is higher than that in the greenhouse drying equipment, because when the short-wavelength solar radiation passes through the greenhouse drying equipment, it is absorbed by the $Z$ armatum placed in the equipment, resulting in the $Z$ armatum heating. The heated $Z$ armatum will emit radiation with a longer wavelength, which cannot penetrate the greenhouse wall, thus increasing the temperature of the enclosed air and causing the temperature inside the greenhouse to be higher than that outside the greenhouse [27]. Therefore, when the moisture content ratio of $Z$ armatum in sunlight tends to be gentle, the moisture content ratio of $Z$ armatum in greenhouse will continue to decline. The three types of $Z$ armatum drying process are directly from the speed-up phase to the speed-down phase without a constant-speed drying process, which also conforms to the drying characteristic curve of porous materials.

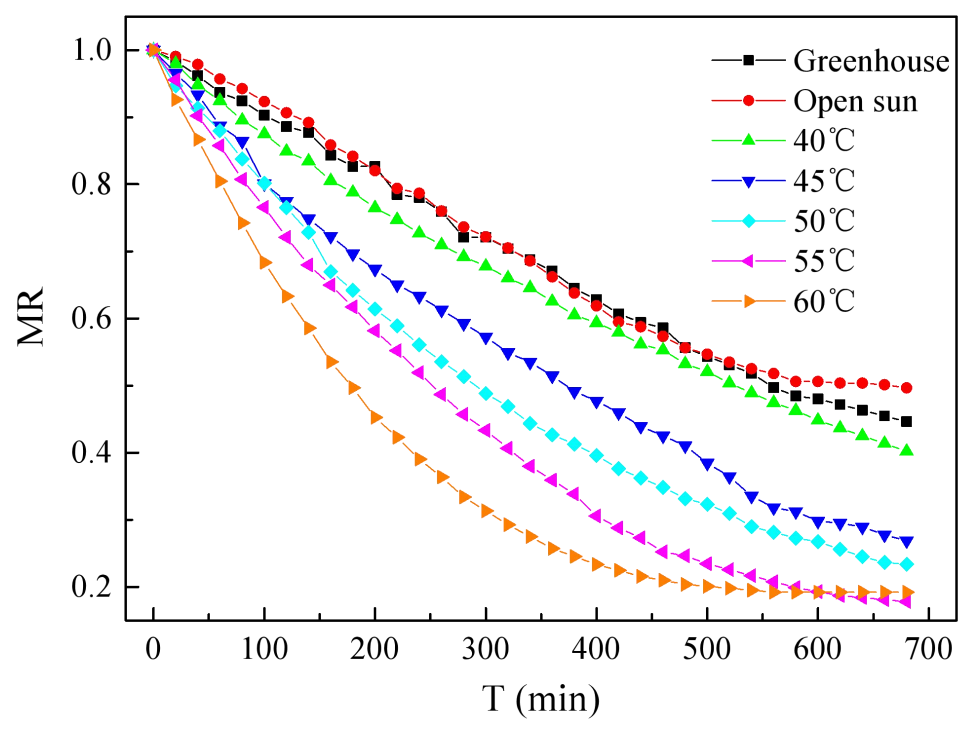

Figure 4. Moisture ratio change of $Z$ armatum with drying time

\subsection{Model fitting of moisture reduction during drying process}

Four semi-theoretical thin-layer drying models were used to fit the MR and T data under different drying treatment methods, and the model parameters and evaluation indexes $\mathrm{R}^{2}$ and RMSE, MBE, and MAE were obtained, as shown in Table 1.

Four fitting statistical parameter results of different drying methods can be obtained from Table $1, \mathrm{R}^{2}$ value changes from 0.9030 to 0.9967 . The $\mathrm{R}^{2}$ fitted by Avhad and Marchetti models are between 0.9677 and 0.9967 , which is higher than the other three dynamic models. The average RMSE values of the four models are 0.0571, $0.0596,0.0328,0.0263$, and the average RMSE values fitted by the Avhad and Marchetti models is the smallest. The range of MBE of Lewis model, Page model, Henderson and Pabis model, Avhad and Marchetti model are $-0.0635 \sim 0.0744,-0.0427 \sim 0.0531,-0.0513 \sim$ $-0.0244,-0.0091 \sim 0.0053$, among which Avhad, Marchetti model fits. The average MBE is -0.0018 , which is lower than the other 3 drying models. The average MBE of the four models were 0.0193, 0.0016, -0.0366 , and 0.0008 , respectively. The average MBE of the Avhad and Marchetti models was the smallest. Therefore, among the fitting results of these four models, the fitting effect of the Avhad and Marchetti model is the 
best description of the drying process of $Z$ armatum. Table 1 is a comparison of the experimental values with the predicted values of the Avhad and Marchetti models. It can be seen that the Avhad and Marchetti models fit the greenhouse drying equipment best.

\subsection{Volatile oil analysis}

According to the analysis results of the essential oil from the NST11.1 standard library search, the composition and content of essential oil from different drying methods are different, mainly including alkenes, alcohols, esters and aldehydes, as shown in Table 3. There are 28 alkenes, 14 alcohols, 2 esters and 2 aldehydes. The results showed that there were 28 kinds of volatile oil in equipment drying, 32 kinds of volatile oil in sunlight drying, 28 kinds of volatile oil in oven drying at $40^{\circ} \mathrm{C}, 28$ kinds of volatile oil in oven drying at $45^{\circ} \mathrm{C}, 25$ kinds of volatile oil in oven drying at $50^{\circ} \mathrm{C}, 26$ kinds of volatile oil in oven drying at $55^{\circ} \mathrm{C}$ and 31 kinds in oven drying at $60^{\circ} \mathrm{C}$. The common components are: linalool, 1-4-Terpineol, p-Menth-2-en-1-ol, stereoisomer (8CI), (+)-Dipentene, 1-Caryophyllene, g-Terpinene, 2-Thujene (7CI, 8CI). The content range of linalool is $42.6226 \sim 46.3660$, the content range of 1-4-Terpineol is $1.1467 \sim 4.0092$, the content range of p-Menth-2-en-1-ol is $0.1271 \sim 0.2283$, the content range of stereoisomer $(8 \mathrm{CI})$ is $16.7101 \sim 19.8515$, the content range of (+)-Dipentene is $0.7450 \sim 1.9778$, the content range of 1-Caryophyllene, g-Terpinene is $0.5078 \sim 1.9247$, the content range of 2-Thujene $(7 \mathrm{CI}, 8 \mathrm{CI})$ is $0.13359 \sim$ 0.3301 . the content of linalool can reach $45.5738 \sim$ $55.3898 \%$ of the volatile oil, which is the main substances of the $Z$ armatum volatile oil [28].

Table 3. Components of volatile oils

\begin{tabular}{|c|c|c|c|c|c|c|c|}
\hline Component & Greenhouse & Open sun & $40^{\circ} \mathrm{C}$ & $45^{\circ} \mathrm{C}$ & $50^{\circ} \mathrm{C}$ & $55^{\circ} \mathrm{C}$ & $60^{\circ} \mathrm{C}$ \\
\hline .alpha.-Guaiene & 0 & 0 & 0.1511 & 0.1189 & 0 & 0.1583 & 0 \\
\hline Bicyclogermacrene & 0.8793 & 0 & 0 & 0 & 0.9595 & 0.4733 & 1.7199 \\
\hline$(+)$-4-Carene & 0.3111 & 0.4196 & 0.6447 & 0.4009 & 0.6787 & 0.7092 & 0 \\
\hline$(+)$-b-Selinene & 0 & 0.5816 & 0 & 0 & 0.33 & 0 & 0.6595 \\
\hline$(+)$-epi-Bicyclosesquiphellandrene & 0 & 0 & 0.2004 & 0.1936 & 0 & 0 & 0 \\
\hline 6-Octenal, 3,7-dimethyl-, (R)- & 0.1412 & 0 & 0.1356 & 0.1519 & 0 & 0 & 0 \\
\hline 1,3,6-Octatriene, 3,7-dimethyl-, (Z)- & 0 & 1.2681 & 0 & 0.9221 & 0 & 0 & 1.0841 \\
\hline $\begin{array}{l}\text { Naphthalene, 1,2,4a,5,6,8a-hexahydro-4, } \\
\text { 7-dimethyl-1-(1-methylethyl)- }\end{array}$ & 0.1748 & 0 & 0.1252 & 0.1431 & 0 & 0 & 0.1376 \\
\hline $\begin{array}{l}\text { 1,5,5-Trimethyl-6-methylene-cyclohexe } \\
\text { ne }\end{array}$ & 0.1684 & 0.2834 & 0.1069 & 0.1145 & 0.1664 & 0 & 0.2651 \\
\hline $\begin{array}{l}\text { 1,6-Octadien-3-ol, 3,7-dimethyl-, } \\
\text { 2-aminobenzoate }\end{array}$ & 0.5601 & 0.5502 & 0.4041 & 0.5412 & 0 & 0.4434 & 0 \\
\hline$\alpha$-Patchoulene & 0 & 0.3027 & 0 & 0 & 0 & 0 & 0 \\
\hline $\begin{array}{l}\text { 1H-Cyclopenta }[1,3] \text { cyclopropa }[1,2] \\
\text { benzene, octahydro-7-methyl-3- } \\
\text { methylene-4-(1-methylethyl)-,[3aS-(3a.a } \\
\text { lpha.,3b.beta.,4.beta.,7.alpha.,7aS*)]- }\end{array}$ & 0 & 0 & 0 & 0 & 0 & 1.1221 & 3.0322 \\
\hline $\begin{array}{l}\text { 1-Hydroxy-1,7-dimethyl-4-isopropyl-2, } \\
\text { 7-cyclodecadiene }\end{array}$ & 0 & 0.1759 & 0 & 0.1471 & 0 & 0 & 0 \\
\hline Caryophyllene & 1.2117 & 1.7663 & 0.785 & 0.8759 & 1.0848 & 0.745 & 1.9778 \\
\hline $\begin{array}{l}\text { Bicyclo[3.1.0]hex-2-ene, } \\
\text { 4-methyl-1-(1-methylethyl)- }\end{array}$ & 0.154 & 0.1359 & 0.2422 & 0.2261 & 0.242 & 0.3301 & 0.1544 \\
\hline Nerolidol 2 & 0 & 0 & 0 & 0 & 0 & 0 & 0.1767 \\
\hline$(+)$-2-Carene & 0 & 0 & 0 & 0 & 0 & 1.3213 & 0.6703 \\
\hline beta.-Phellandrene & 4.0817 & 9.897 & 0 & 0 & 5.2166 & 4.3867 & 0 \\
\hline $\begin{array}{l}\text { 3-Cyclohexen-1-ol, 4-methyl-1- } \\
\text { (1-methylethyl)-, (R)- }\end{array}$ & 1.1467 & 1.5824 & 2.1676 & 1.4219 & 2.6955 & 4.0092 & 2.3761 \\
\hline $\begin{array}{l}\text { Azulene, 1,2,3,3a,4,5,6,7-octahydro-1, } \\
\text { 4-dimethyl-7-(1-methylethenyl)-, } \\
\text { [1R-(1.alpha.,3a.beta.,4.alpha.,7.beta.)]- }\end{array}$ & 0 & 0 & 0 & 0 & 0.145 & 0 & 0.3051 \\
\hline $\begin{array}{l}\text { Bicyclo[3.1.1]hept-2-ene-2-methanol, } \\
\text { 6,6-dimethyl- }\end{array}$ & 0 & 0.1218 & 0 & 0.1476 & 0 & 0.1297 & 0 \\
\hline L-.alpha.-Terpineol & 0 & 0 & 0 & 0 & 0.5939 & 0 & 0.6628 \\
\hline .beta.-Humulene & 0.2557 & 0 & 0 & 0 & 0 & 0 & 0 \\
\hline $\begin{array}{l}\text { Cyclohexanecarboxylic acid, pentadecyl } \\
\text { ester }\end{array}$ & 0 & 0.238 & 0 & 0 & 0 & 0 & 0 \\
\hline $\begin{array}{l}\text { Cyclohexanemethanol,4-ethenyl-.alpha., } \\
\text { alpha.,4-trimethyl-3-(1-methylethenyl)- }\end{array}$ & 0.3785 & 0.2289 & 0.2474 & 0.2298 & 0 & 0 & 0.1542 \\
\hline
\end{tabular}




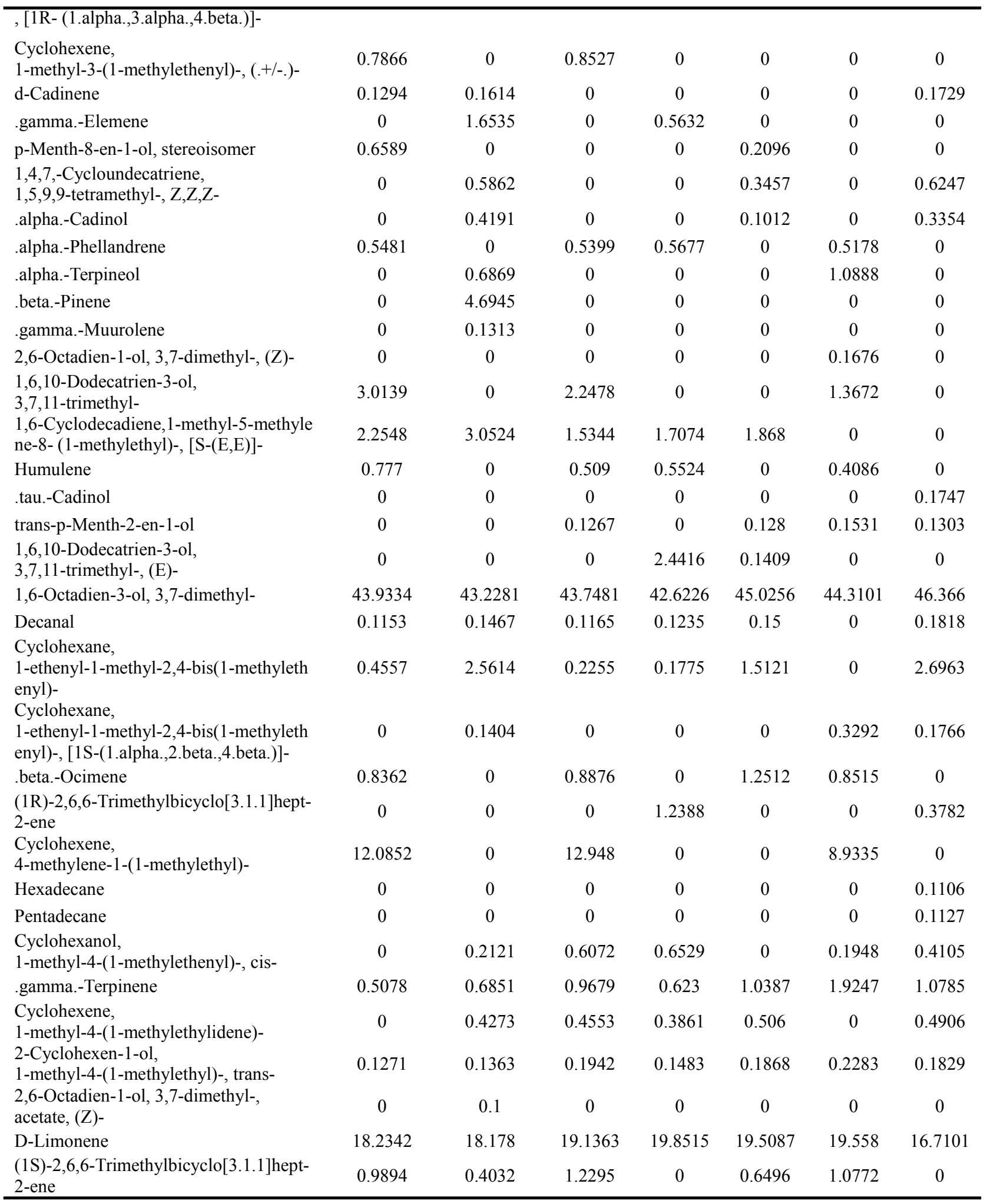

\section{Conclusion}

$Z$ armatum obtained in the seven drying conditions in this paper. In terms of color, the color of dried $Z$ armatum at $40^{\circ} \mathrm{C}$ is the best under hot wind conditions, but it is lower than the greenhouse. The $Z$ armatum obtained by the greenhouse drying equipment is cyan-green, which can prevent the browning of $Z$ armatum during the drying process. Drying $Z$ armatum numb degree in $45^{\circ} \mathrm{C}$ conditions is the highest. The numbness of $Z$ armatum in greenhouse was low, which may be because the high temperature in greenhouse destroyed the numbness of $Z$ armatum. The numb degree of $Z$ armatum increased first and then decreased slowly. Therefore, the drying process of $Z$ armatum should not be too long, so as to prevent the thermal sensitive hydroxy - zanthoxylin from being broken and reduce the numb feeling strength of $Z$ armatum. The opening rate of 
$Z$ armatum under the greenhouse was slightly lower than that of hot wind $40^{\circ} \mathrm{C}$, but higher than that under other conditions. Compared with the results of other drying conditions, although the numb degree of $Z$ armatum dried by the greenhouse drying equipment is low, but the color and opening ratio are higher than other conditions. The fitting results of models show that the $\mathrm{R}^{2}$ fitted by the Avhad and Marchetti models are larger than those fitted by other models, and the RMSE is lower than those fitted by other models, which can accurately predict the change trend of the moisture ratio with drying time in the $Z$ armatum drying process under the three drying modes.

\section{Credit authorship contribution statement}

Dong Xia: Methodology, Software, Validation, Investigation, Writing original draft preparation, Visualization. Lingyan Jiang: Methodology, Software, Formal analysis, Investigation, Data curation. Jinxi Cheng: Software, Formal analysis, Investigation, Data curation, Visualization. Xiaoyan Hou: Methodology, Software, Formal analysis, Investigation, Data curation, Visualization. Shanshan Li: Conceptualization, Validation, Writing review and editing, Supervision. Qingying Luo: Writing review and editing, Supervision, Project administration, Funding acquisition. Guanghui Shen: Methodology, Supervision, Project administration. Hejun Wu: Formal analysis, Resources, Funding acquisition. Anjun Chen: Resources, Funding acquisition, Conceptualization. Zhiqing Zhang: Conceptualization, Validation, Resources, Writing review and editing, Project administration, Funding acquisition.

\section{Conflicts of interest}

The authors declare no conflicts of interest.

\section{Acknowledgments}

This work was supported by the Key Research \& Development Project [18ZDYF1175] of the Science \& Technology Department of Sichuan Province, China.

\section{References}

[1] Wang, Yi.-ran., Li Y.-H., Guo, T., Li H.-L., Tan Y.-F., Zhang Z., Zhang X.-G., Mai S.-Y., Zhang J.-Q.,2018. Measurement of pharmacokinetics and tissue distribution of three bioactive constituents from Zanthoxylum armatum DC in rat plasma and tissues through UFLC-MS/MS. Journal of Chromatography B. 1087-1088, 80-89.

[2] Nooreen, Z., Singh, S., Singh, D. K., Tandon, S., Ahmad, A., Luqman, S., 2017. Characterization and evaluation of bioactive polyphenolic constituents from Zanthoxylum armatum DC., a traditionally used plant. Biomed. Pharmacother. 89, 366-375.

[3] Dissa, A.O., Bathiebo, D.J., Desmorieux, H.,
Coulibaly, O., Koulidiati, J., 2011. Experimental characterisation and modelling of thin layer direct solar drying of Amelie and Brooks mangoes. Energy. 36(5), 2517-2527.

[4] Seerangurayar T., Al-Ismaili, A.M., Janitha Jeewantha, L.H., Al-Habsi, N.A., 2019. Effect of solar drying methods on color kinetics and texture of dates. Food Bioprod. Process. . 116, 227-239.

[5] Tunde-Akintunde, T. Y., 2011. Mathematical modeling of sun and solar drying of chilli pepper. Renew. Energy. 36(8), 2139-2145.

[6] Fudholi, A., Sopian, K., Alghoul, M.A., Ruslan, M.H., Othman, M.Y., 2015. Performances and improvement potential of solar drying system for palm oil fronds. Renew. Energy. 78, 561-565.

[7] Chauhan, P.S., Kumar, A., 2018. Thermal modeling and drying kinetics of gooseberry drying inside north wall insulated greenhouse dryer. Appl. Therm. Eng., 130(5), 587-597.

[8] Saleh, A., Badran, I., 2009. Modeling and experimental studies on a domestic solar dryer. Renew. Energy. 34(10), 2239-2245.

[9] Khadraoui, A.E., Hamdi, I., Kooli, S., Guizani, A., 2019. Drying of red pepper slices in a solar greenhouse dryer and under open sun: Experimental and mathematical investigations. Innov. Food Sci. Emerg. Technol. 52, 262-270.

[10] Panwar, N. L., Kaushik, S. C., Kothari, S., 2013. Thermal modeling and experimental validation of solar tunnel dryer: a clean energy option for drying surgical cotton. Int. J. Low-Carbon Technol.. 0, $1-13$.

[11] Roberts, J. S., Kidd, D. R., Padilla-Zakour, O., 2008. Drying kinetics of grape seeds. Journal of Food Eng.. 89(4), 460-465.

[12] Benseddik, A., Azzi, A., Zidoune, M.N., Allaf, K.,2018. Mathematical empirical models of thin-layer airflow drying kinetics of pumpkin slice. Engineering in Agriculture, Environment and Food. 11(4), 220-231.

[13] Erick César, L.-V., Ana Lilia, C.-M., Octavio, G.-V., Isaac, P.F., Rogelio, B.O., 2019. Thermal performance of a passive, mixed-type solar dryer for tomato slices (Solanum lycopersicum). Renew. Energy. 147(1), 845-855.

[14] Avhad, M.R., Marchetti J.M., 2016. Mathematical modelling of the drying kinetics of Hass avocado seeds. Ind. Crops Prod.. 91, 76-87.

[15] Onwude, D.I., Hashim, N., Janius, R.B., Nawi, N.M., 2016. Modeling the thin - layer drying of fruits and vegetables: A review. Compr. Rev. Food. Sci. Food Saf.. 15(3), 599-618.

[16] Zhang, Q.-A., Song, Y., Wang, X., Zhao, W.-Q., Fan, X.-H., 2016. Mathematical modeling of debittered apricot (Prunus armeniaca L.) kernels during thin-layer drying. CyTA-J. Food. 14(4), 509-517.

[17] Dissa, A.O., Bathiebo, J., Kam, S., Savadogo P.W., 
Desmorieux H., Koulidiati J., 2009. Modelling and experimental validation of thin layer indirect solar drying of mango slices. Renew. Energy. 34(4), 1000-1008.

[18] Rosa, D.P, Cantú-Lozano, D., Luna-Solano, G., 2015. Mathematical modeling of orange seed drying kinetics. Cienc. Agrotec. 39(3), 291-300.

[19] Keneni, Y. G., Hvoslef-Eide, A. K. (Trine), Marchetti, J. M., 2019. Mathematical modelling of the drying kinetics of Jatropha curcas L. seeds. Ind. Crop. Prod. . 132, 12-20.

[20] Komolafe, C.A., Ojediran, J.O., Ajao, F.O., Dadac, O.A., Afolabi, Y.T., Oluwaleye, I.O., Alake, A.S., 2019. Modelling of moisture diffusivity during solar drying of locust beans with thermal storage material under forced and natural convection mode. Case Stud Therm Eng. 15, 100542.

[21] Standardization Administration of China (SAC), 2013. Agricultural Standards of China: GB/T 30391-2013. China standards press, Prickly ash. Beijing (China). (In Chinese)

[22] Sriwichai, T., Sookwong, P., Siddiqui, M. W., Sommano, S. R., 2019. Aromatic profiling of Zanthoxylum myriacanthum (makwhaen) essential oils from dried fruits using different initial drying techniques. Industrial Crops and Products. 133, 284-291.

[23] Phuyal, Nirmala; Jha, Pramod Kumar; Prasad Raturi, Pankaj; Rajbhandary, Sangeeta (2018). Zanthoxylum armatum DC.: Current knowledge, gaps and opportunities in Nepal. Journal of Ethnopharmacology. 229, 326-341.

[24] Jie, Y., Li, S., Ho, C.-T., 2019. Chemical composition, sensory properties and application of Sichuan pepper (Zanthoxylum genus). Food Sci Hum Well. 8(2), 115-125.

[25] Jiang, L., Kubota, K., 2004. Differences in the Volatile Components and Their Odor Characteristics of Green and Ripe Fruits and Dried Pericarp of Japanese Pepper (Zanthoxylum piperitumDC.). $J$. Agric. Food Chem.. 52(13), 4197-4203.

[26] Perea-Flores, M.J., Garibay-Febles, V., Chanona-Perez, J.J., 2012. Mathematical modelling of castor oil seeds (Ricinus communis) drying kinetics in fluidized bed at high temperatures. Ind. Crop. Prod. 38, 64-71.

[27] Chauhan, P.S., Kumar, A., 2016. Performance analysis of greenhouse dryer by using insulated north-wall under natural convection mode. Energy. Rep. 2, 107-116.

[28] Liu, Yuping., Li, Qingru., Yang, Wenxi., Sun, Baoguo., Zhou, Ying., Zheng, Yang., Huang, Mingquan., Yang, Wenjie., 2020. Characterization of the Potent Odorants in Zanthoxylum armatum DC Prodr. Pericarp Oil by Application of Gas Chromatographyâ Mass

Spectrometryâ Olfactometry and Odor Activity Value. Food Chemistry. 139, 126-564. 